\title{
Optimization of Adsorption Parameters for Removal of Carbaryl Insecticide Using Neem Bark Dust by Response Surface Methodology
}

\author{
Soumya Chattoraj ${ }^{1}$ - Naba K. Mondal ${ }^{1} \cdot$ Bikash Sadhukhan $^{1} \cdot$ Palas Roy $^{1}$. \\ Tapas Kumar Roy ${ }^{1}$
}

Received: 24 February 2016 /Revised: 29 June 2016 / Accepted: 30 June 2016 / Published online: 19 July 2016

(C) Springer Science+Business Media Singapore 2016

\begin{abstract}
Adsorptive removal of carbaryl from aqueous solutions by neem bark dust (NBD) was investigated in a batch method under laboratory conditions. At first, the effects of particle size, stirring rate, and contact time on the adsorption process were studied. The optimum value of particle size, stirring rate, and contact time were $200 \mu \mathrm{m}, 250 \mathrm{rpm}$, and $25 \mathrm{~min}$, respectively. Subsequently, response surface methodology (RSM) was applied to investigate the effects of other operating parameters such as solution $\mathrm{pH}(2-10)$, adsorbent dose $(0.01-1 \mathrm{~g})$, and initial concentration (5-20 ppm). The optimization of the process parameters and calculation of the effects and interactions of process variables were done by using Box-Behnken design (BBD) which is a subset of RSM. The independent variables were precisely optimized by making use of an objective function called "desirability function." Based on the adsorption capacity and economical use of adsorbent, the input parameters were optimized by setting two different sets of criteria (I and II). The desirability of two different sets were 1.00 and 0.822 , respectively, which explains that the estimated function can well represent the experimental model. The optimized result revealed that the NBD can be an effective adsorbent for the removal of carbaryl from an aqueous system. The adsorption of carbaryl on NBD was best analyzed with the Langmuir isotherm and the pseudo-second order kinetic model. From the kinetic study, the maximum adsorption capacity was found to be
\end{abstract}

Naba K. Mondal

nkmenvbu@gmail.com

1 Environmental Chemistry Laboratory, Department of Environmental Science, The University of Burdwan, Golapbag,

Burdwan 713104, West Bengal, India
$142.85 \mathrm{mg} \mathrm{g}^{-1}$. Thermodynamic data confirmed the feasibility and spontaneous nature of the adsorption process.

Keywords Adsorption · Carbaryl · Neem bark dust . Box-Behnken design · Analysis of variance · Desirability function
Abbreviations
NBD Neem bark dust
RSM Response surface methodology
BBD Box-Behnken design

\section{Introduction}

Nowadays, the contamination of surface water and groundwater by pesticides has become an alarming environmental problem owing to their extensive application in agriculture practice. Pesticides are considered as one of the possible contaminants in natural water because when these are applied on crops in agricultural fields, they get transported to the soil and then to surface water or groundwater resources due to their leaching and runoff losses [1]. Other sources are generally due to improper disposal of the empty pesticide packets, wind erosion, and discharge from industries [2]. Keeping in mind the viable importance of water, the potential toxicity, carcinogenicity, and mutagenic effects caused by pesticide contamination of water bodies are a vexing political and environmental question [3]. Such problem is the most severe in developing countries where groundwater is one of the major drinking water resources [4]. Due to the harmful effect of pesticides on human health and environment, many countries have already imposed strict laws on drinking water and wastewater treatment [5]. According to the WHO, the permissible 
limit of the pesticide residue in water is $0.1 \mu \mathrm{g} \mathrm{L} \mathrm{L}^{-1}$ for an individual pesticide and for all pesticides a total of $0.5 \mu \mathrm{g} \mathrm{L}^{-1}$ [6]. Therefore, the removal of pesticides from water by suitable methods is an urgent necessity. There are many methods available for removal of pesticides from aqueous medium including chlorination [7], ultrasound combined with photo-Fenton treatment [8], photocatalytic degradation $[9,10]$, advanced oxidation processes [11], aerobic degradation [12] electrodialysis membranes [13], ozonation [14], and adsorption [15]. Among these conventional methods for the removal of pesticides, adsorption technique is found to be the most economical, effective, highly flexible in design, and simple as well as offers scope for regeneration of adsorbent materials [3]. Therefore, adsorption technique has drawn wide attention of the investigators for the removal of pesticides from contaminated water samples [16-20]. In this perspective, intense research interest has been generated for exploring cost-effective, ecofriendly, and easily available adsorbent particularly of biological origin [16-23].

Carbaryl (1-naphthyl methyl carbamate) is widely used as an insecticide on fruits, vegetables, cotton, forages, and other crops in many countries [22]. Carbaryl kills beneficial insects, e.g., honey bees, crustaceans, and earthworms [24]. It is also likely to be carcinogenic to humans [25]. Thus, excessive use of carbaryl is a great threat to the environment.

The various adsorbents like Porogen-treated banana pith carbon [26], different soils [23, 27, 28], clay [29], Pistia stratiotes biomass [16], and Lemna major biomass [23] were used to achieve effective removal of carbaryl from aqueous medium.

Previously, neem bark dust (NBD) had been used effectively to remove many pollutants like $\mathrm{Zn}$ (II) and $\mathrm{Cd}$ (II) [30, 31], $\mathrm{Cr}(\mathrm{VI})$ [32], As(III) [20], and dyes [33-35] from aqueous solutions, but no such information has been reported on the removal of carbaryl by NBD. Thus, to find the higher value of adsorption capacity compared to other adsorbents, NBD was chosen to remove carbaryl insecticide from aqueous solutions.

In most of the adsorption studies, the effects of individual parameters on the adsorption process have been investigated by keeping the level of other operating factors constant [16, 22]. In those cases, to establish the optimum levels, a large number of variable experiments were required to be executed [36]. Therefore, to overcome such limitations, several types of statistical experimental design methods have been applied. Response surface methodology (RSM) is one of the preferred experimental design methods for investigation of the combined effect of different variables in the adsorption process, as it requires a limited number of experiments [36]. RSM is a useful package of statistical methods for modeling different problems even in the presence of complex interactions. It explains the influence of several operating parameters to the output with proper explanation [37]. Presently, it is a widely applied technique in different adsorption studies [16, 22, 23, 35, 36, 38]. The prime intention of using RSM is to attain lesser process variability, yield of higher amount, and better authentications of output response within a short period of time [36]. Keeping in mind the above fact, the main objective of the study is to evaluate the adsorption process of carbaryl onto NBD from water and optimization of the process via RSM. The operating parameters were solution $\mathrm{pH}(2-10)$, adsorbent dose $(0.01-1 \mathrm{~g})$, and initial concentration (5-20 ppm).

The experimental data were statistically validated by performing analysis of variance (ANOVA) and lack-of-fit test to evaluate the significance of the model using Box-Behnken design (BBD). BBD is sphere-shaped, rotating RSM design that consists of the middle points of the edge and the central point of a cube circumscribed on a sphere. It is a collection of three interlocking $2^{2}$ factorial designs in which all points are present on the surface of a sphere surrounding the center of the design [38]. Previously, many researchers have successfully applied BBD in adsorption study to remove many pollutants from aqueous solution [18, 25, 34, 35].

In the present study, BBD was selected as the core experimental model. It was preferred among various subsets from RSM as this design helped to explore the behavior of multicomponent adsorption. Desirability function was used to identify optimal conditions where the maximum adsorption capacity was obtained for the removal of carbaryl using NBD to ensure the high uptake capacity at low adsorbent dosage and high carbaryl concentration. The desirability function is a method for the execution of optimum points of input factors that can determine optimum results for one or more responses. The desirability procedure has two steps including finding the levels of the independent variables and at the same time producing the most desirable predicted responses on the dependent variables while maximizing the overall desirability about the controllable factors [39].

\section{Materials and Methods}

\section{Chemicals}

A fresh solution of 4-nitrobenzenediazonium fluoborate (Sigma-Aldrich, $99.9 \%$ pure) was prepared in methanol $(0.03 \% w / v)$ and used as the main reagent. Analytical grade $\mathrm{NaOH}$ was used for spectrophotometric estimation. An analytical standard pure sample of carbaryl was recrystalized from a technical grade sample supplied by Bayer. Carbaryl solutions were made in analytical grade $\mathrm{CaCl}_{2}$. Optima grade methanol was used as the solvent for the extraction. Further, all standard solutions were placed at room temperature for use.

\section{Adsorbent Collection and Preparation}

The neem bark (Azadirchta indica) used in the present study was collected from the campus of the university, The 
university of Burdwan, W.B., India. The collected bark was cut into pieces and washed thoroughly to remove foreign materials, then drenched in $0.1 \mathrm{~N} \mathrm{NaOH}$ followed by $0.1 \mathrm{~N}$ $\mathrm{H}_{2} \mathrm{SO}_{4}$ [35]. Thereafter, the pieces of bark were air dried for a fortnight and ground into different particle sizes using different metal sieves having different mesh sizes and stored in clean jars for further experiments.

\section{Characterization of Adsorbent}

The physiochemical properties of the adsorbent like ash content; bulk density; particle density; moisture; $\mathrm{pH}$; $\mathrm{pH}_{\mathrm{zpc}}$; porosity; surface area; moisture content; and carbon, hydrogen, and nitrogen content were determined. The specific surface area of the adsorbent is measured by adsorption of nitrogen at $77 \mathrm{~K}$ using the molecular area of nitrogen as $0.162 \mathrm{~nm}^{2}$, and the measurement of the BET surface area of the adsorbent in the study was conducted using a surface area analyzer (model: Nova-2200e, Quantachrome Corporation, Boynton Beach, USA). The $\mathrm{pH}$ of zero-point charge $\left(\mathrm{pH}_{\mathrm{ZPC}}\right)$ was determined based on the previous method [40]. The elemental composition of the adsorbent including carbon, hydrogen, and nitrogen was analyzed. In addition, scanning electron microscopy (SEM) analysis was carried out using a scanning electron microscope (HITACHI, S-530, Scanning Electron Microscope and ELKO Engineering, B.U. Burdwan) at $15 \mathrm{kV}$ to study the surface morphology of the adsorbent after adsorption of carbaryl. Finally, the Fourier transform infrared (FTIR) spectra of NBD after carbaryl adsorption was recorded with Fourier transform infrared spectrophotometer (PerkinElmer, FTIR, Model-RX1 Spectrometer, USA) in the range of $400-4400 \mathrm{~cm}^{-1}$.

\section{Batch Adsorption Procedure}

The spectrophotometric determination of carbaryl was done by the following method [41]. Five milliliters of $0.5(\mathrm{~N}) \mathrm{NaOH}$ solution was added to $5 \mathrm{~mL}$ of carbaryl solution, then $5 \mathrm{~mL}$ of $0.03 \%(w / v)$ methanolic solution of p-nitrobenzene diazonium fluoborate was also mixed. The mixture was then diluted up to $20 \mathrm{~mL}$ with methanol. After $20 \mathrm{~min}$ by using the UVVIS spectrophotometer (Systronics, Vis Double Beam Spectrophotometer 1203), the absorbance of the greenishblue color of the resulting solution was measured at a wavelength of $590 \mathrm{~nm}$ [42]. The detection limit of this method is $0.1 \mu \mathrm{g} \mathrm{mL}^{-1}[41]$.

During the present study, at the first optimum value of the particle size, stirring rate and contact time were selected. Thereafter, the effect of $\mathrm{pH}(2-10)$, adsorbent dose (0.1-1 g/100 $\mathrm{mL})$, and initial carbaryl concentration (5$20 \mathrm{mg} \mathrm{L}^{-1}$ ) was evaluated via RSM. Samples were collected from the flasks at predetermined time intervals for analyzing the residual carbaryl concentration in the solution. The amount of carbaryl adsorbed in milligram per gram was calculated by using Eq. 1 .

$q_{e}=\frac{\left(\mathrm{C}_{\mathrm{i}}-\mathrm{C}_{\mathrm{e}}\right) \mathrm{V}}{\mathrm{m}}$

where $C_{i}$ and $C_{e}$ are carbaryl concentrations $\left(\mathrm{mg} \mathrm{L}^{-1}\right)$ before and after adsorption, respectively, $\mathrm{V}$ is the volume of adsorbate in liters, and $\mathrm{m}$ is the weight of the adsorbent in grams. The percentage of removal of carbaryl was calculated from the following equation:

$\operatorname{Removal}(\%)=\frac{\left(\mathrm{C}_{\mathrm{i}}-\mathrm{C}_{\mathrm{e}}\right)}{\mathrm{C}_{\mathrm{i}}} \times 100$

The adsorption experiments were carried out in triplicate, and the mean values were taken in the data analysis. The control experiments were performed without the addition of adsorbent which confirmed that the adsorption of carbaryl on the walls of glass was found negligible.

\section{Experimental Design}

The optimization of carbaryl adsorption using NBD was carried out by three independent variables including solution $\mathrm{pH}$, adsorbent dose, and initial carbaryl concentration. The ranges and levels of the independent variables performed in this study are tabulated in Table 1. The removal percentage of carbaryl was taken as output (response) of the system. The quadratic equation model for predicting the optimal point is expressed by using Eq. 3 .

$$
\begin{aligned}
Y= & \beta_{0}+\sum_{i=1}^{k} \beta_{i} x_{i}+\sum_{i=1}^{k} \sum_{j=1}^{k} \beta_{i j} x_{i} x_{j} \\
& +\sum_{i=1}^{k} \beta_{i i} x_{i i}^{2}+\varepsilon
\end{aligned}
$$

where $Y$ is the response variable; $\beta_{0}$ is the intercept; $\beta_{i}, \beta_{i j}$, and $\beta_{\mathrm{ii}}$ are coefficients of the linear effect, double interactions; $\mathrm{x}_{\mathrm{i}}$ and $\mathrm{x}_{\mathrm{j}}$ are the independent variables; and $\varepsilon$ is error [22]. A total of 17 experiments were performed in triplicate according to the scheme mentioned in Table 1. Design Expert Version 7.1.6 [43] was used for regression and graphical analysis of the data obtained. The effect of interaction between different operating parameters can be explained by response surface 3D plots. The optimum values of the selected variables were

Table 1 Variables and levels considered for the adsorption of carbaryl onto NBD

\begin{tabular}{llll}
\hline Name (factor) & Units & Low & High \\
\hline Initial concentration (A) & ppm & 5 & 20 \\
pH (B) & & 2 & 10 \\
Biomass dose (C) & $\mathrm{g}$ & 0.01 & 0.1 \\
\hline
\end{tabular}


established by solving the regression equation also by examining the ramp desirability plots. The name ramp is derived from the appearance of its graph. The ramp plot provides the optimum values of input factors and output responses. The inconsistency in dependent variables was justified by the multiple coefficients of determination. $R^{2}$ and model equation predicted the optimum value and consequently explained the interaction between the operating parameters within the definite range.

\section{Desorption Study}

For regeneration of carbaryl adsorbed NBD desorption, an experiment was carried out by using $\mathrm{NaOH}$ by following our previously established and published method [23]. Finally, the desorption percentage of carbaryl was calculated by Eq. 4 .

$\operatorname{Desorption}(\%)=\frac{\left(\mathrm{C}_{\mathrm{a}}-\mathrm{C}_{\mathrm{d}}\right)}{\mathrm{C}_{\mathrm{a}}} \times 100$

where $\mathrm{C}_{\mathrm{a}}$ is the adsorbed carbaryl concentration and $\mathrm{C}_{\mathrm{d}}$ is the concentration of carbaryl after desorption.

\section{Results and Discussion}

\section{Characterization of Adsorbent}

\section{The Physiochemical Properties}

The physiochemical properties of NBD like surface area, pHzpc, $\mathrm{pH}$, conductivity, moisture content, bulk density, particle density, and porosity were determined and are presented in Table 2.

Table 2 Physiochemical characteristics of adsorbent

\begin{tabular}{lc}
\hline Analysis & Value \\
\hline Ash content $(\%)$ & 12.70 \\
Bulk density $\left(\mathrm{g} / \mathrm{cm}^{3}\right)$ & 0.621 \\
Particle density $\left(\mathrm{g} / \mathrm{cm}^{3}\right)$ & 0.923 \\
Porosity $(\%)$ & 32.71 \\
Moisture $(\%)$ & 1.8 \\
$\mathrm{pH}$ & 7.1 \\
$\mathrm{pH}$ & 6.80 \\
Surface area $\left(\mathrm{m}^{2} / \mathrm{g}\right)$ & 328.1 \\
Volatile matter $(\%)$ & 87.28 \\
$\mathrm{C}(\%)$ & 43.23 \\
$\mathrm{H}(\%)$ & 4.39 \\
$\mathrm{~N}(\%)$ & 0.93 \\
\hline
\end{tabular}

\section{SEM Analysis}

SEM analysis is a useful tool for the analysis of the surface morphology of an adsorbent [28]. It can be seen from the SEM image of the NBD (Fig. 1) that the pores were completely filled after the adsorption of carbaryl. This observation indicates that carbaryl is adsorbed well inside the pores.

\section{FTIR Analysis}

The FTIR spectrum of NBD after adsorption is displayed in Fig. 2. The intensity of the peaks for carbaryl-loaded NBD $\left(713,868,1030,1448,1789,3000 \mathrm{~cm}^{-1}\right)$ was either maximized or shifted slightly from the FTIR spectral analysis of $\operatorname{NBD}\left(660,774,1025,1222,1593,2924,3305 \mathrm{~cm}^{-1}\right)$ which has been reported in our previous research [23]. The broad and strong band at $3305 \mathrm{~cm}^{-1}$ indicates the presence of $-\mathrm{OH}$ stretching. The peak at $2924 \mathrm{~cm}^{-1}$ is attributed to methylene $\mathrm{C}-\mathrm{H}$ asymmetric stretching. The peak at $1593 \mathrm{~cm}^{-1}$ was due to the presence of the carboxylate group. The characteristic peaks at 1222,1025 , and $774 \mathrm{~cm}^{-1}$ related to aromatic phosphates ( $\mathrm{P}-\mathrm{O}-\mathrm{C}$ stretching), $\mathrm{C}-\mathrm{O}$ stretching, and $\mathrm{C}-\mathrm{Cl}$ stretching vibration [44]. After carbaryl adsorption, the intensity of methylene $\mathrm{C}-\mathrm{H}$ asymmetric stretching and carboxylate and phosphate bands of the adsorbent are different from those of the adsorbent before adsorption of carbaryl. The results suggest that carbaryl interacts with the functional groups present on the surface of NBD.

\section{Effect of Particle Size}

In the first stage of batch adsorption experiments, effect of particle size was checked by varying particle sizes $(200$ $400 \mu \mathrm{m})$ at a speed of $200 \mathrm{rpm}, \mathrm{pH} 6$ with adsorbent dose $0.11 \mathrm{~g}$, contact time $15 \mathrm{~min}$, and $20 \mathrm{ppm}$ initial concentration of carbaryl. The influence of particle size on the extent of adsorption (Fig. 3) clearly indicated that carbaryl adsorption decreased with increasing particle size. For larger particles, the diffusion limitations are usually more important and, as a result, the number of molecules that reach the internal surface of the adsorbent is small resulting in low carbaryl adsorption

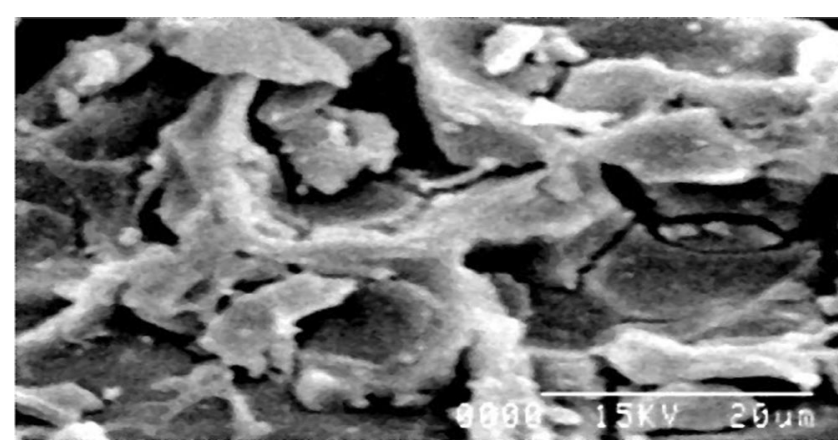

Fig. 1 SEM image of NBD after adsorption of carbaryl onto NBD 
Fig. 2 FTIR of NBD after adsorption of carbaryl onto NBD

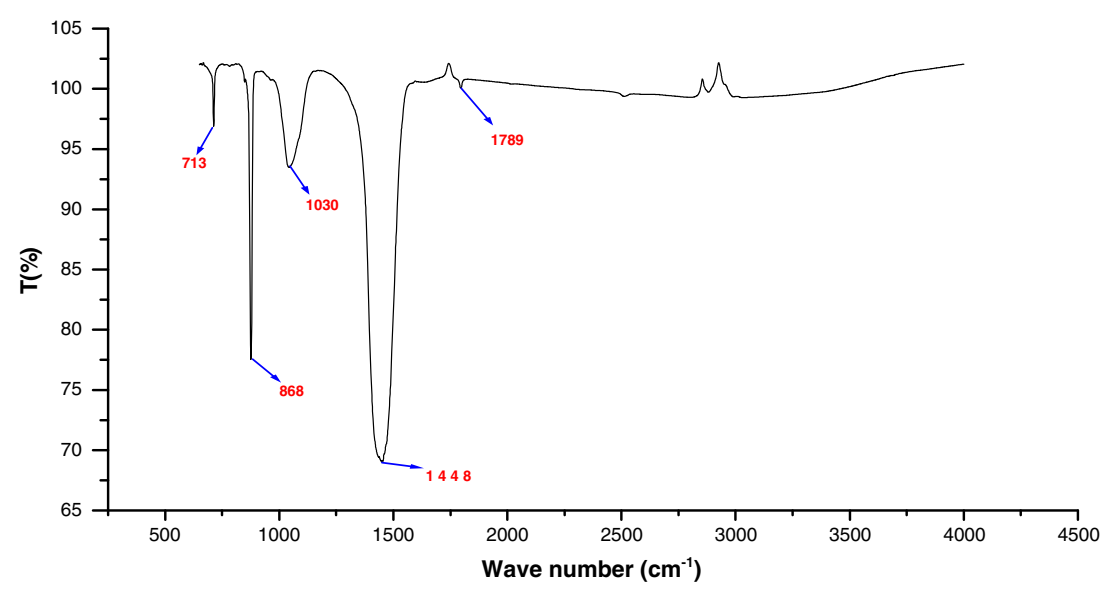

capacity [45]. The breaking down of the large particles into smaller ones may serve to open the sealed channels in the adsorbent, which then become available for adsorption. The surface area and the number of active pores of the adsorbent increase with the decrease in particle size and therefore result in high carbaryl adsorption capacity [46]. For further experiments, a size fraction of $200 \mu \mathrm{m}$ was selected because of its higher removal capacities.

\section{Effect of Stirring Rate}

The stirring rate in adsorption study is an important parameter that can enhance a certain turbulence which is beneficial for closer contact between the adsorbate and the adsorbent [47]. The effect of the stirring rate was found out by varying speeds from 100 to $400 \mathrm{rpm}$ at $\mathrm{pH} 6$ with adsorbent dose of $0.1 \mathrm{~g}$, contact time of $15 \mathrm{~min}$, and $20 \mathrm{ppm}$ initial concentration of carbaryl. The influence of the stirring rate on the extent of adsorption is shown in Fig. 4. It is revealed from the above

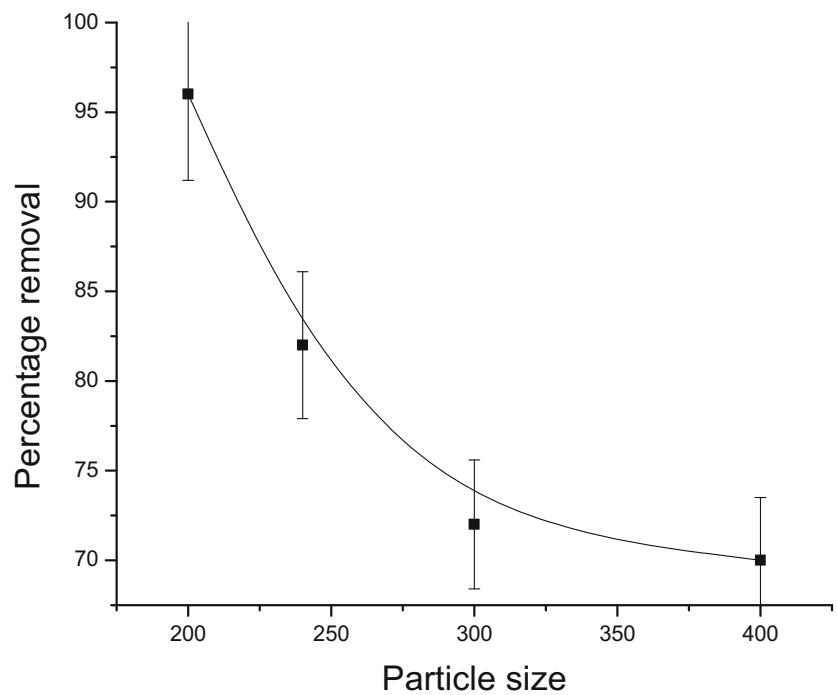

Fig. 3 Effect of particle size ( $\mu \mathrm{m})$ on adsorption of carbaryl onto NBD (bar in each point indicate error bar) figure that the carbaryl adsorption depends upon the stirring rate. The percentage adsorption is less at lower stirring rate and increases with increased stirring rate up to $250 \mathrm{rpm}$ and thereafter shows no further change. Hence, with increasing shaking rate, adsorption was increased due to better contact between the adsorbent and the adsorbate [29]. Higher stirring rate forces the more efficient mass transfer of carbaryl molecules from bulk solution to the surface of the adsorbent as well as lesser time consumption [48]. Similar observations have been published in adsorption of carbaryl onto alluvial soil [28]. Therefore, for further studies, $250 \mathrm{rpm}$ was kept constant.

\section{Effect of Contact Time}

It is essential to assess the effect of contact time required to reach equilibrium for designing batch adsorption experiments [23]. Therefore, the effect of contact time $(5-60 \mathrm{~min})$ on adsorption of carbaryl onto NBD was also investigated. The

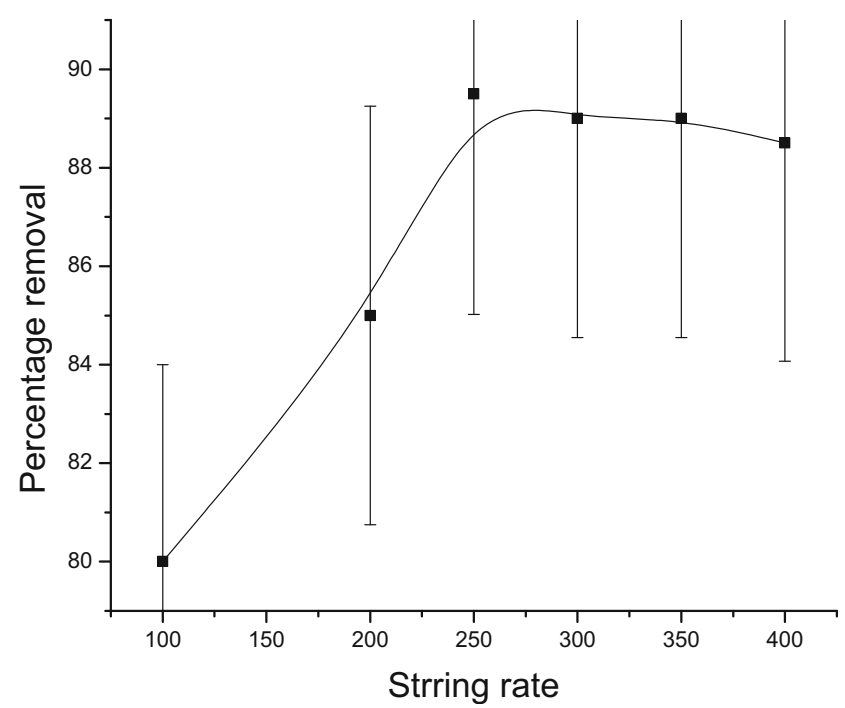

Fig. 4 Effect of stirring rate (rpm) on adsorption of carbaryl onto NBD (bar in each point indicate error bar) 
adsorption of carbaryl increased with rise in contact time up to $25 \mathrm{~min}$, and after that a further increase in contact time did not affect the carbaryl adsorption process (Fig. 5). Similar findings for carbaryl adsorption onto other adsorbents have been reported elsewhere [23, 41].

\section{Statistical Analysis}

After choosing the optimum value of the particle size, stirring rate, and equilibrium contact time, a two-level BBD was used to analyze the adsorption of carbaryl onto NBD as a function of several parameters, viz., $\mathrm{pH}$ (A), adsorbent dose (B), and initial concentration $(\mathrm{C})$. The ANOVA of carbaryl adsorption capacity $\mathrm{q}_{\mathrm{e}}(\mathrm{mg} / \mathrm{g})$ is given in Table 3 . The statistical analysis of variance (ANOVA) included the Fisher's $F$ test with its associated probability $p>F$ and the correlation coefficient $R^{2}$ which measures the fitness of regression model and lack of fit, respectively [21]. The larger value of $F$ and the smaller value of $p$ are needed for significant corresponding coefficient terms [22, 37]. In this analysis, the $F$ value of 435.03 with probability of $<0.0001, R^{2}$ of 0.9982 , and coefficient of variation of $1.04 \%$ confirmed that the model was highly significant and the experiments were precise and consistent. Further, adequate precision ratio was calculated to verify competence of the quadratic regression model [49]. Adequate precision ratio greater than 4 is desirable [37]. In the present study, the value calculated ratio is .542 which also validates the model [50]. The $F$ and $p$ values for lack of fit were 0.47 and 0.7590 (probability $>F$ ), respectively, which indicate no significance. Nonsignificant lack of fit is good for the model to fit [37]. Among all the terms, the linear effects of A and B were found to be significant since the $p$ values were $<0.0001$ for the factors. An empirical relationship between the response and the independent variables has been expressed by the following

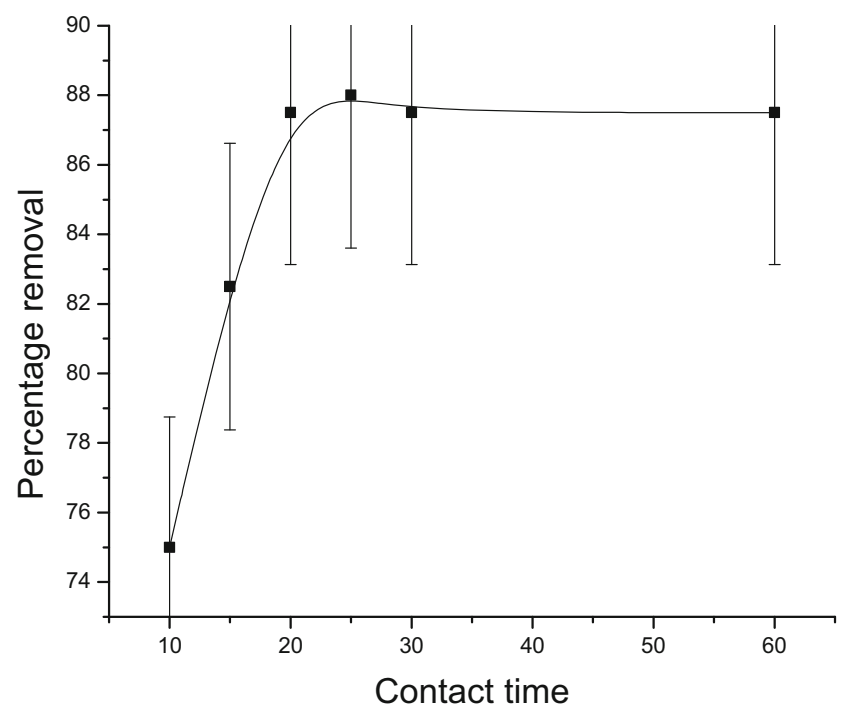

Fig. 5 Effect of contact time ( $\mathrm{min}$ ) on adsorption of carbaryl onto NBD (bar in each point indicate error bar) quadratic model equation. Based on statistical significance, Eq. 5 can be written in coded terms as

$$
\begin{aligned}
\% \text { Removal }(Y)= & +90.80-3.34^{*} A+5.94^{*} B \\
& +0.013^{*} C-1.13^{*} A^{*} B+1.12^{*} A^{*} C \\
& +0.55^{*} B^{*} C 19.88^{*} A^{2} \\
& +3.27^{*} B^{2}-8.63 * C^{2}
\end{aligned}
$$

where $\mathrm{Y}$ is the response of carbaryl removal capacity of NBD at the end of adsorption time. $\mathrm{A}, \mathrm{B}$, and $\mathrm{C}$ correspond to the independent variables of solution $\mathrm{pH}$, adsorbent dose, and initial carbaryl concentration, respectively.

This equation reveals how the individual variable (quadratic) or double interaction affected carbaryl removal from aqueous solution by NBD. A combined effect between $\mathrm{pH}$ and adsorbent dose (AB) was found to be the most significant interaction factor due to the $p$ value of 0.0481 . All the quadratic terms, viz., A, B, C, D, AB, AC, BC, A, A ${ }^{2}, \mathrm{~B}^{2}$, and $\mathrm{C}^{2}$, were found to be significant owing to their high $F$ values and low $p$ values [21]. Therefore, it can safely be concluded that $\mathrm{pH}(\mathrm{A})$, adsorbent dose (B), and initial concentration (C) play an important role in carbaryl adsorption onto NBD. The plot between experimental (actual) and predicted values of percentage carbaryl adsorption capacity is presented in Fig. 6. The figure indicates that both the values are in reasonable agreement with each other. It also suggests a good correlation between input and output variables that could be drawn by the model developed. Adjusted $R^{2}$ and predicted $R^{2}$ values were found to be 0.9959 and 0.9945 , respectively, which indicate that there was reasonable agreement between the actual and the predicted values. The coefficient of variation and the standard deviation were found to be 1.04 and 0.84 (Table 3). The minimum value of the standard error design, 0.447 around the centroid, also indicates that the present model can be used to navigate the design space (Fig. 7). The normal residual plot between probability and internally studentized residuals (Fig. 8) shows that the residuals were distributed normally with minimum deviations, hence there was no transformation needed $[37,51,52]$. The response surface 3D plots (Fig. 9) were described by the regression model and used to express the relationships between factors on carbaryl adsorption capacity on NBD under the sets of conditions and treatment levels tested (Table 1). To determine the adequacy of the models depicting the removal of carbaryl by NBD, two different tests, i.e., the sequential model sum of squares and the model summary statistics, were conducted. The corresponding results are tabulated in Tables 4 and 5, respectively. The value of leverage, internally studentized residuals, externally studentized residuals, DFFITS, and Cook's distance of the data can be obtained from diagnostic case statistics. The results portray that the leverage value was within 0 to 1 . The 
Table 3 Analysis of variance (ANOVA) for percentage removal of carbaryl onto NBD

\begin{tabular}{|c|c|c|c|c|c|c|}
\hline Source & Sum of squares & $d f$ & Mean square & $F$ value & $\begin{array}{l}p \text { value } \\
\text { Prob }>\text { F }\end{array}$ & \\
\hline Model & 2735.4 & 9 & 303.9 & 435.0 & $<0.0001$ & Significant \\
\hline $\mathrm{A}-\mathrm{pH}$ & 52.0 & 1 & 52.0 & 74.4 & $<0.0001$ & \\
\hline $\mathrm{B}$ - dose & 176.2 & 1 & 176.2 & 252.2 & $<0.0001$ & \\
\hline $\mathrm{C}$ - concentration & 0.0 & 1 & 0.0 & 0.0 & 0.9816 & \\
\hline $\mathrm{AB}$ & 4.0 & 1 & 4.0 & 5.7 & 0.0481 & \\
\hline $\mathrm{AC}$ & 2.1 & 1 & 2.1 & 3.0 & 0.1274 & \\
\hline $\mathrm{BC}$ & 0.5 & 1 & 0.5 & 0.7 & 0.4186 & \\
\hline$A^{2}$ & 1296.1 & 1 & 1296.1 & 1855.1 & $<0.0001$ & \\
\hline $\mathrm{B}^{2}$ & 42.6 & 1 & 42.6 & 61.0 & 0.0001 & \\
\hline $\mathrm{C}^{2}$ & 148.7 & 1 & 148.7 & 212.8 & $<0.0001$ & \\
\hline Residual & 4.9 & 7 & 0.7 & & & \\
\hline Lack of fit & 1.9 & 4 & 0.5 & 0.5 & 0.7590 & Not significant \\
\hline Pure error & 3.0 & 3 & 1 & & & \\
\hline Cor total & 2740.3 & 16 & & & & \\
\hline Std. dev. & 0.84 & & $R^{2}$ & & & 0.9982 \\
\hline Mean & 80.38 & & $\operatorname{Adj} R^{2}$ & & & 0.9959 \\
\hline C.V. $\%$ & 1.04 & & Pred $R^{2}$ & & & 0.9945 \\
\hline PRESS & 15.16 & & Adeq precision & & & 61.542 \\
\hline
\end{tabular}

Cook's distance (range must be within \pm 1 ) and studentized residuals (limit of the studentized residuals is \pm 3 sigma) illustrate the normal distribution and constant variance of the residuals, the effective fitness, linearity of the model, and the independence [53]. The limit of the internally studentized residuals is \pm 3 sigma. DFFITS (limit lies in between +2 and -2 ) is a diagnostic tool that demonstrates how influential a point is in a statistical regression [54]. The analysis of diagnostic case

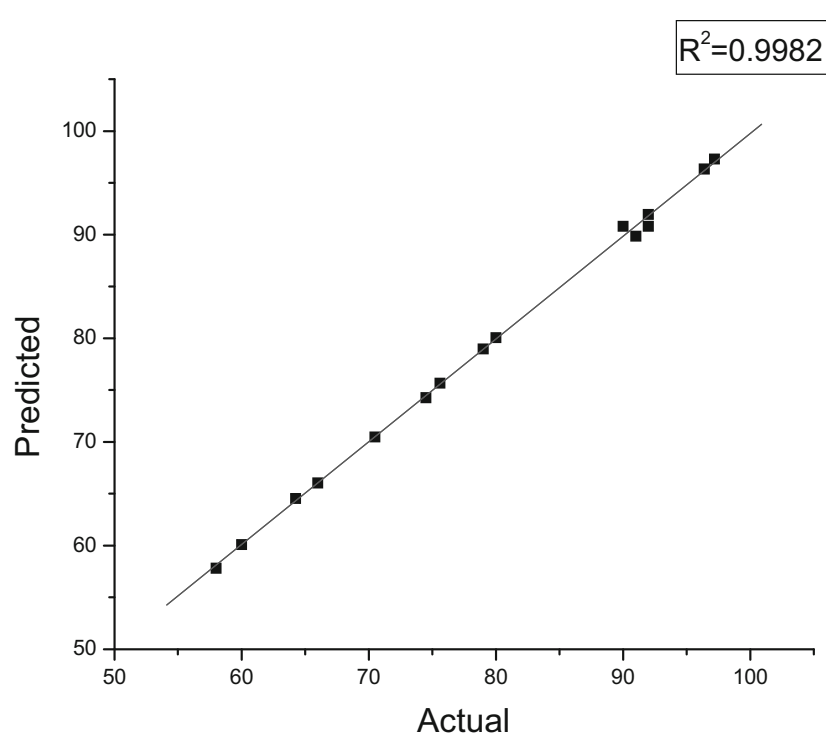

Fig. 6 Comparison of the experimental data (line) with those predicted data (symbols) statistics of data shows that the model fits well to optimize the independent variables for the removal of carbaryl.

A comparison of the effects of all factors under the optimal conditions of carbaryl adsorption to the neem bark was assessed by perturbation plot (Fig. 10). The sharp curvature of $\mathrm{pH}(\mathrm{A})$, adsorbent dose (B), and initial concentration (C) indicate that the carbaryl adsorption is highly affected by those variables.

\section{Adsorption Isotherm}

The adsorption isotherm is the most extensively employed criterion for representing the equilibrium states of an adsorption system. It can give useful information regarding the adsorption process; it explains the equilibrium relationship between the adsorbate concentrations in the liquid phase with the adsorbent in a particular condition [55]. The equation parameters and the basic thermodynamic concept of the isotherm models offer some idea about the adsorption mechanism as well as the surface properties and affinity of the adsorbent [55]. There are varieties of isotherm models to describe equilibrium relationships, but not a single model is universally applicable. A particular model may or may not be valid in a particular case. Hence, it is important to establish the most appropriate isotherm model for the equilibrium data for evaluating the applicability of the adsorption process [55].

In view of this fact, in this study isotherm data were applied to Langmuir, Freundlich, Temkin, and D-R models at different temperatures and the outcome of their linear regressions was used to select the model with the best fit. 
Fig. 7 Standard error of design on adsorption of carbaryl onto NBD

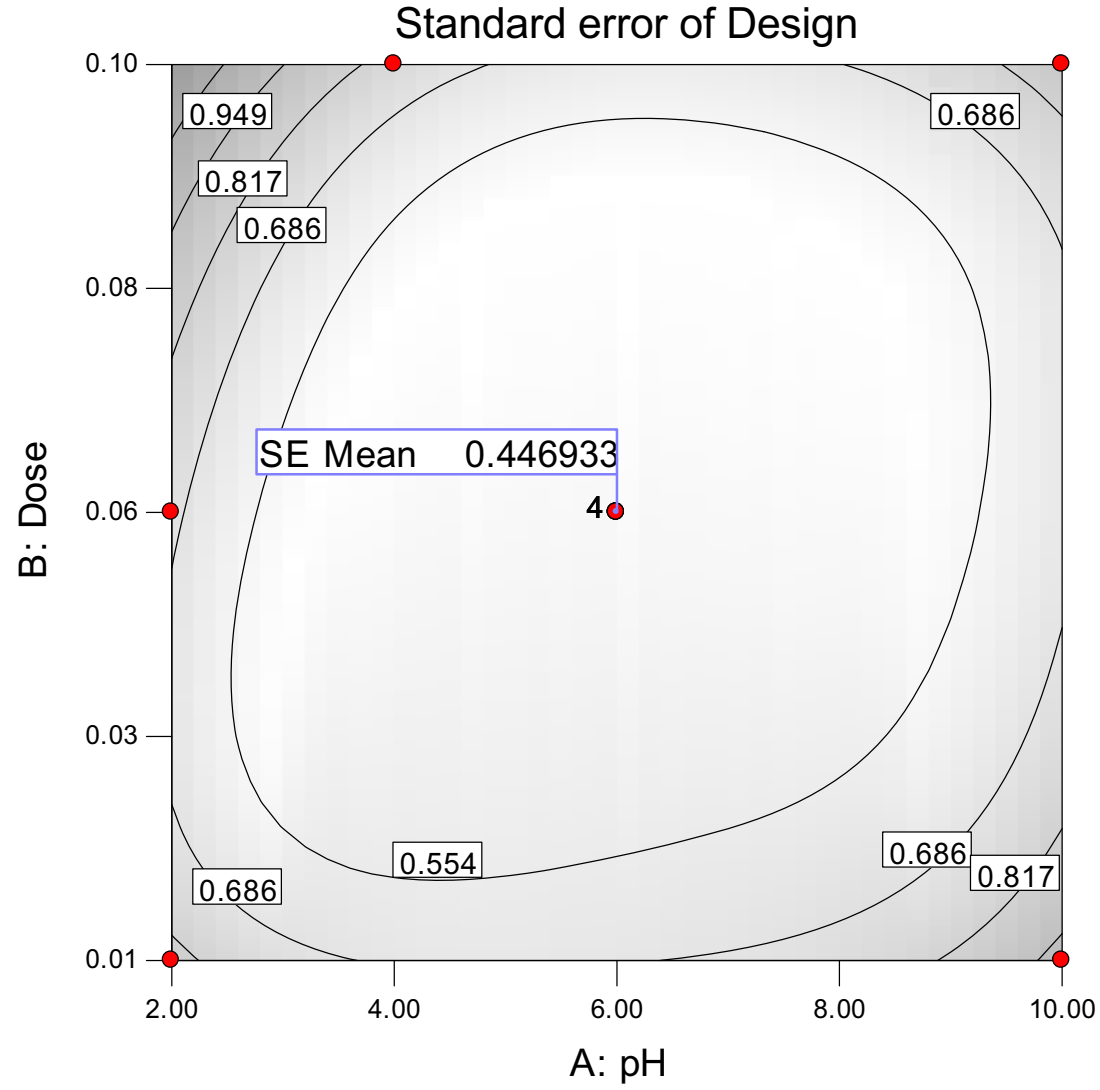

The linear form of the Langmuir and Freundlich models [56] with values of ensuing parameters and regression coefficients $\left(R^{2}\right)$ are listed in Table 6. The

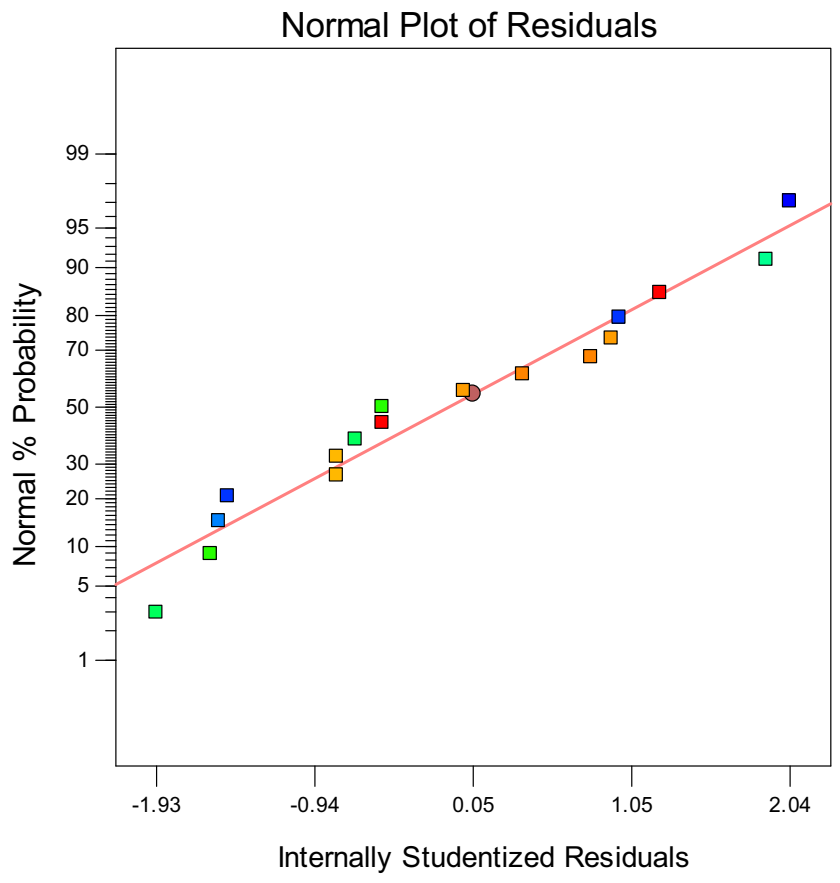

Fig. 8 Normal plots of residuals vs internally studentized residuals straight lines generated from the experimental data for three different temperatures (Fig. 11) with a good correlation coefficient $\left(R^{2} 0.994\right.$ to 0.995$)$ showed the acceptability of the Langmuir isotherm over other adsorption isotherms used in this present study. The fitness of the adsorption data to the Langmuir isotherm explains that the binding energy on the whole surface of the adsorbent was uniform in nature and adsorption occurred through formation of a monolayer. A similar finding was shown on adsorption of amitraz pesticide onto clay [57].

Compared with the Langmuir and Freundlich isotherm models, the Temkin isotherm equation [55] did not fit well with the experimental data. The constants $\mathrm{K}_{\mathrm{T}}$ and $\mathrm{B}$ were determined from the intercept and slope of the plot between $\mathrm{q}_{\mathrm{s}}$ and $\operatorname{lnC}_{\mathrm{f}}$. However, as seen from Table 6, the Temkin constant $\mathrm{B}$ increases with increasing temperature indicating endothermic adsorption [55]. Further, higher $\mathrm{K}_{\mathrm{T}}$ values at all temperatures suggest strong interaction between the carbaryl and the adsorbent surface [55]. Smaller values of the Temkin constant $B$ also suggested that adsorption of carbaryl on NBD was favorable.

The $\mathrm{D}-\mathrm{R}$ isotherm model [45] was chosen to estimate the heterogeneity of the surface energies. The plots between $\operatorname{lnq}_{\mathrm{s}}$ and $\varepsilon^{2}$ gave straight lines at all 

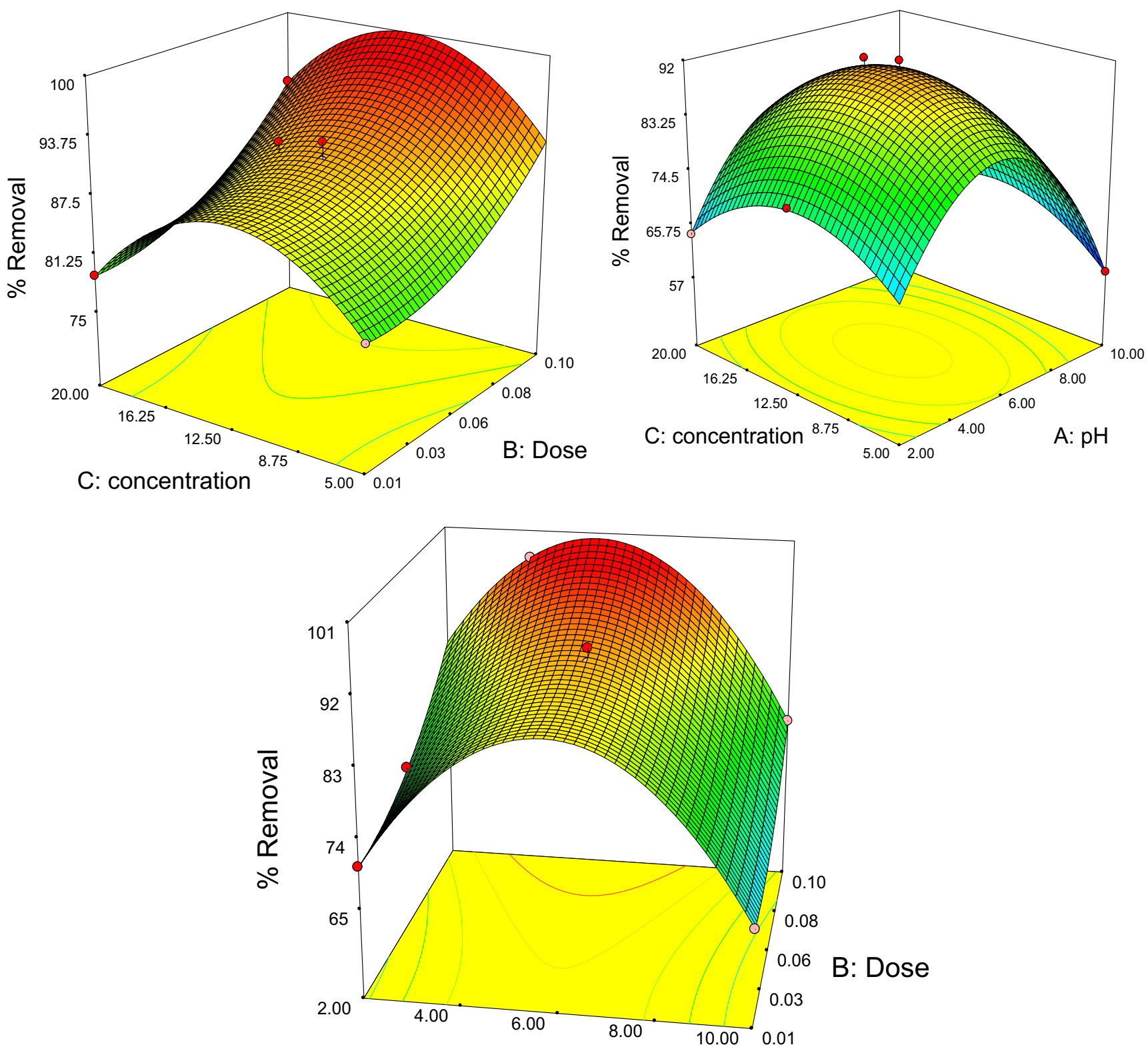

$\mathrm{A}: \mathrm{pH}$

Fig. 9 Response surface plots showing the effect of independent variables on carbaryl adsorption onto NBD

temperatures; the values of constants $\mathrm{q}_{\mathrm{m}}$ and $\beta$ thus obtained are given in Table 6. The model constant gives an idea about the mean free energy $\mathrm{E}\left(\mathrm{kJ} \mathrm{mol}^{-1}\right)$ of adsorption per mole of the adsorbate which in turn
Table 4 Adequacy of the model tested

\begin{tabular}{lllllll}
\hline Source & Sum of squares & $d f$ & Mean square & $F$ value & $p$ value Prob $>$ F & \\
\hline Mean vs total & 109834.4 & 1 & 109834.4 & & & \\
Linear vs mean & 857.6 & 3 & 285.8667 & 1.973929 & 0.1678 & \\
2FI vs linear & 444.3327 & 3 & 148.1109 & 1.029733 & 0.4205 & Suggested \\
Quadratic vs 2FI & 1433.452 & 3 & 477.8174 & 683.913 & $<0.0001$ & Aliased \\
Cubic vs quadratic & 1.890565 & 4 & 0.472641 & 0.472641 & 0.7590 & \\
Residual & 3 & 3 & 1 & & & \\
Total & 112574.7 & 17 & 6622.043 & & & \\
\hline
\end{tabular}


Table 5 Model summary statistics for carbaryl adsorption onto NBD

\begin{tabular}{lllllll}
\hline Source & Sum of squares & $d f$ & Mean square & $F$ value & $p$ value Prob $>$ F & \\
\hline Linear & 1879.675 & 10 & 187.9675 & 187.9675 & 0.0006 & \\
2FI & 1435.343 & 7 & 205.0489 & 205.0489 & 0.0005 & Suggested \\
Quadratic & 1.890565 & 4 & 0.472641 & 0.472641 & 0.7590 & Aliased \\
Cubic & 0 & 0 & & & & \\
Pure error & 3 & 3 & 1 & & & \\
\hline
\end{tabular}

can give information about the type of sorption mechanism. E can be calculated using the relationship [58].

$E=\frac{1}{\sqrt{2 \beta}}$

The estimated values of $\mathrm{E}$ for the present study were found to be $>8 \mathrm{~kJ} \mathrm{~mol}^{-1}$ at all temperatures (Table 5) which implies that adsorption of carbaryl on NBD is chemisorption in nature [58].

\section{Adsorption Kinetics}

In order to find adsorption kinetics, pseudo-first order and pseudo-second order kinetic models were applied at optimum value of initial concentration. The equation of adsorption kinetics [59], the values of $\mathrm{K}_{1}$, the correlation coefficients $\left(R^{2}\right)$, and the theoretical equilibrium adsorption capacity $\left(\mathrm{q}_{\mathrm{s}}\right)$ are presented in Table 7. The $R^{2}$ values (Table 6) suggested that adsorption of carbaryl onto NBD does not follow pseudo-first order kinetics. It thus confirmed that the pseudo-first order model was not appropriate for describing the adsorption kinetics of carbaryl onto NBD. On the contrary, the kinetic data

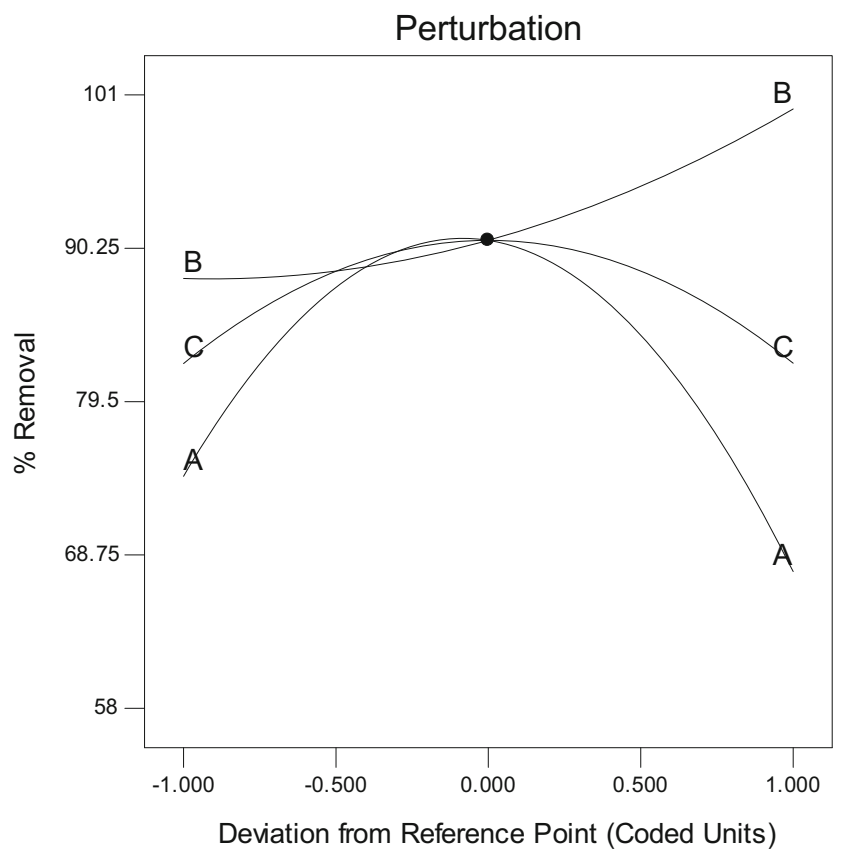

Fig. 10 Perturbation plot of carbaryl adsorption onto NBD showed excellent fit to the pseudo-second order equation at all concentrations studied. The plot of $t / q_{t}$ against $t$ (at all the studied concentrations) is shown in Fig. 12. The pseudosecond order rate constant $\mathrm{K}_{2}$, the theoretical $\mathrm{q}_{\mathrm{S}}$ value, and the corresponding linear regression correlation coefficient value $\left(R^{2}\right)$ are given in Table 6. From Table 6, it is evident that the correlation coefficient for the pseudo-second order kinetic plot is high $\left(R^{2}>0.99\right)$. So, it can be inferred that the adsorption process proceeds through pseudo-second order mechanism rather than a pseudo-first order mechanism. The best fit to the pseudo-second order kinetics also means that the adsorption process may be chemisorption in nature, based on the assumption that the rate-limiting step involves valence forces through sharing or exchange of electrons [60]. In addition, the calculated $\mathrm{q}_{\mathrm{s}}$ value also agrees with the experimental data in the case of the pseudo-second order kinetic model. Similar findings for carbaryl adsorption onto other adsorbents have been reported elsewhere [16, 23].

\section{Thermodynamics Study}

In order to fully understand the nature of the adsorption process, the thermodynamic parameters such as change in free energy $\left(\Delta G^{\circ}\right)$, change in enthalpy $\left(\Delta H^{\circ}\right)$, and change in entropy $\left(\Delta S^{\circ}\right)$ must be calculated. These parameters can be estimated by considering the equilibrium constants at different temperatures. The change in free energy $\left(\Delta G^{\circ}\right)$ for adsorption process was planned by using the following equations:

$\Delta G^{0}=-R T \ln k_{c}$

$k_{c}=C_{n} / C_{e}$

$\Delta G^{0}=\Delta H^{0}-T \Delta S^{0}$

where $C_{n}$ is equilibrium carbaryl concentration on NBD $\left(\mathrm{mg} \mathrm{L}^{-1}\right)$.

The value of enthalpy change $\left(\Delta \mathrm{H}^{\circ}\right)$ and entropy change $\left(\Delta \mathrm{S}^{\circ}\right)$ was calculated from the slope and intercept of the plot $\Delta \mathrm{G}^{\circ}$ vs T (Fig. 13). Table 8 provides the values of thermodynamic parameters. The values of free energy change $\left(\Delta \mathrm{G}^{\circ}\right)$ ensured that the adsorption process was spontaneous and thermodynamically favorable under the experimental conditions. The decrease in value of $\Delta \mathrm{G}^{\circ}$ with increasing temperature strongly implied the occurrence of significant adsorption. 
Table 6 Summary of parameters for various isotherm models

\begin{tabular}{|c|c|c|c|c|c|}
\hline \multirow{2}{*}{$\begin{array}{l}\text { Isotherm } \\
\text { model }\end{array}$} & \multirow[t]{2}{*}{ Equation } & & \multicolumn{3}{|c|}{ Constants at different temperature } \\
\hline & & & $293 \mathrm{~K}$ & $303 \mathrm{~K}$ & $313 \mathrm{~K}$ \\
\hline \multirow[t]{2}{*}{ Langmuir isotherm } & \multirow{2}{*}{$\frac{C_{e}}{q_{e}}=\frac{C_{e}}{q_{m}}+\frac{1}{k_{L} q_{m}}$} & $\mathrm{~K}_{\mathrm{L}}\left(\mathrm{L} \mathrm{mg}^{-1}\right)$ & 0.0578 & 0.082 & 0.165 \\
\hline & & $R^{2}$ & 0.994 & 0.969 & 0.996 \\
\hline \multirow[t]{3}{*}{ Freundlich isotherm } & \multirow{3}{*}{$\log q_{e}=\log k_{F}+\log c_{e}\left(\frac{1}{n}\right)$} & $1 / \mathrm{n}$ & 0.893 & 0.547 & 0.234 \\
\hline & & $\mathrm{K}_{\mathrm{F}}\left(\mathrm{mg} \mathrm{g}^{-1}\right)$ & 1.07 & 1.08 & 1.27 \\
\hline & & $R^{2}$ & 0.988 & 0.961 & 0981 \\
\hline \multirow[t]{3}{*}{ Temkin isotherm } & \multirow[t]{3}{*}{$q_{e}=B \ln K_{T}+B \ln c_{e}$} & $\mathrm{~B}$ & 0.014 & 0.051 & 0.054 \\
\hline & & $\mathrm{K}_{\mathrm{T}}\left(\mathrm{Lm} \mathrm{g}^{-1}\right)$ & 3.07 & 0.39 & 0.220 \\
\hline & & $R^{2}$ & 0.990 & 0.938 & 0.969 \\
\hline \multirow[t]{3}{*}{$\mathrm{D}-\mathrm{R}$ isotherm } & \multirow[t]{3}{*}{$\ln q_{e}=\ln q_{m}-\beta \varepsilon^{2}$} & $\mathrm{~B}\left(\mathrm{mmol}^{2} \mathrm{j}^{-2}\right)$ & $4.82 \times 10^{-9}$ & $6.71 \times 10^{-9}$ & $7.2151 \times 10^{-9}$ \\
\hline & & $\mathrm{E}\left(\mathrm{KJ} \mathrm{mol}^{-1}\right)$ & 10.19 & 8.63 & 8.32 \\
\hline & & $R^{2}$ & 0.913 & 0.953 & 0.932 \\
\hline
\end{tabular}

Positive value of enthalpy change $\left(\Delta \mathrm{H}^{0}\right)$ revealed the endothermic nature of the adsorption process. The carbaryl molecules had to shift more than one water molecule for their adsorption, and this resulted in the endothermicity of the adsorption process. In addition, $\Delta \mathrm{H}^{\circ}$ data are also used for distinguishing between physical adsorption and chemical adsorption. When the enthalpy change is greater than $60 \mathrm{~kJ} \mathrm{~mol}^{-1}$, the adsorption is typically associated with chemical adsorption, and if it is less than $40 \mathrm{~kJ} \mathrm{~mol}^{-1}$, the adsorption should be associated with physical adsorption [61]. This study depicted that the enthalpy change is higher than $40 \mathrm{~kJ} \mathrm{~mol}^{-1}$. Therefore, chemisorption dominates the adsorption of carbaryl molecules onto NBD. Simultaneously, in the present study $\Delta S^{\circ}$ value was positive. This observation suggests the increased disorder and randomness at the solidsolution interfaces as well as the affinity of carbaryl molecules towards adsorption onto NBD in aqueous solutions. Similar

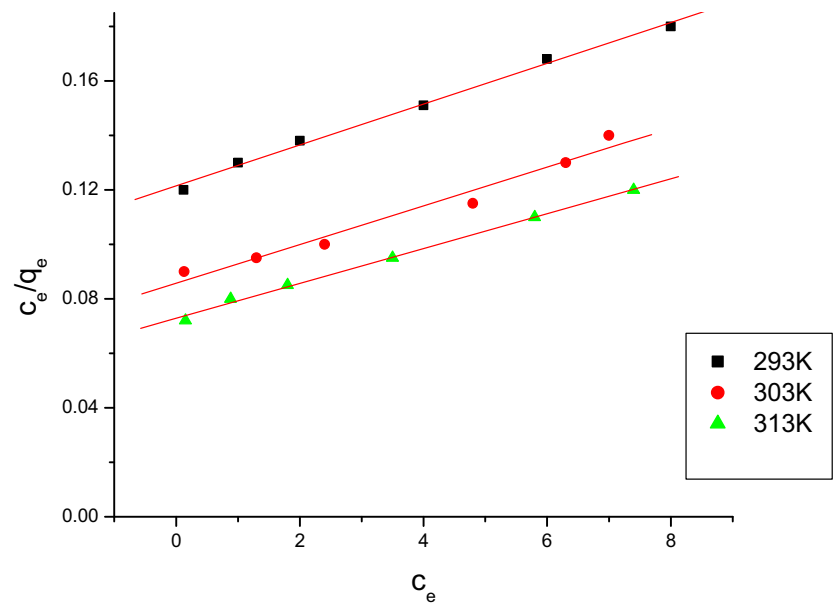

Fig. 11 Langmuir isotherm for adsorption of carbaryl onto NBD at different temperature phenomenon has been observed for adsorption of carbaryl onto four Indian soils [22].

\section{Optimization Using the Desirability Function}

In statistical optimization, a multiple response method was applied for optimization of any combination of four goals, specifically solution $\mathrm{pH}$, adsorbent dose, initial concentration, and percentage of removal. Required goals were selected for each operating parameter and response from the "optimization" menu of the Design-Expert software. The probable goals present in the menu were as follows: maximize, minimize, target, within range, none (for responses only), and set to an exact value (factors only). A maximum and a minimum level were provided for each parameter included [36]. From the menu, "weights" can be allocated to each goal to adjust the form of its particular desirability function. Finally, the goals were united into an overall desirability function. Desirability is a purposeful function that ranges from 0 to 1 at the goal. The goal searching was started randomly by the software at a starting point and brought the steepest slope to a maximum. The overall solution of the optimized result is represented by ramp plots.

Table 7 Summary of parameters for various kinetic models

\begin{tabular}{lll}
\hline Kinetic model & Equation & Constants \\
\hline $\begin{array}{l}\text { Pseudo-first } \\
\quad \text { order }\end{array}$ & $\log \left(q_{e}-q_{t}\right)=\log q_{e}-\frac{k_{1}}{2.303} t$ & $R^{2}=0.962$, \\
Pseudo & $\frac{t}{q_{t}}=\frac{1}{k_{2} q_{e}^{2}}+\frac{t}{q_{e}}$ & $R^{2}=0.994$ \\
$\quad$ second-order & & $\mathrm{K}_{2}=0.0049 \mathrm{~g} \mathrm{mg}^{-1} \mathrm{~min}^{-1}$ \\
& & $\mathrm{q}_{\mathrm{s}}=142.85 \mathrm{mg} \mathrm{g}^{-1}$ \\
\hline
\end{tabular}

Where $\mathrm{q}_{\mathrm{t}}$ is the amount of carbaryl adsorbed $\left(\mathrm{mg} \mathrm{g}^{-1}\right)$ at time $\mathrm{t}, \mathrm{K}_{1}$ $\left(\min ^{-1}\right)$ is the Lagergren rate constant of first order adsorption, and $\mathrm{k}_{2}$ $\left(\mathrm{g} \mathrm{mg}^{-1} \mathrm{~min}^{-1}\right)$ is the second order adsorption rate constant 


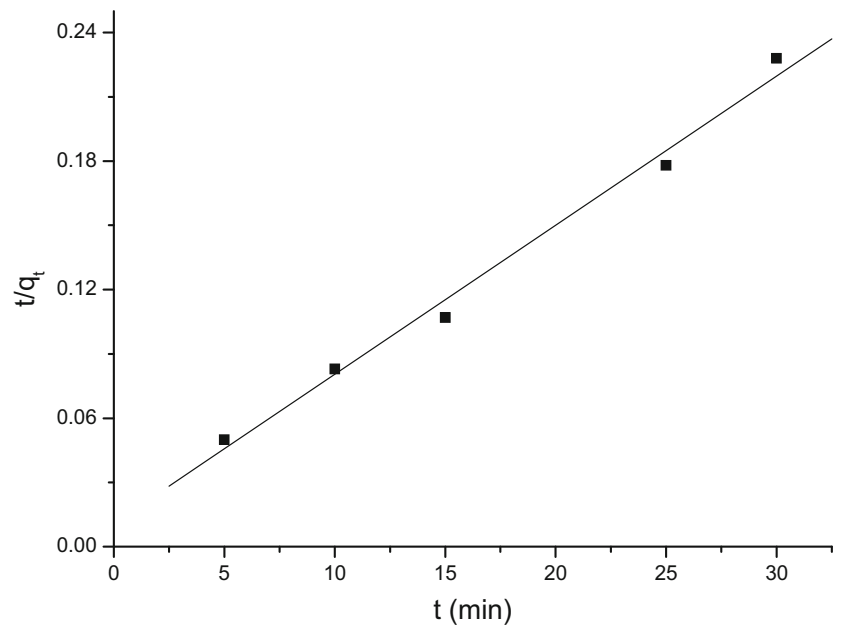

Fig. 12 Pseudo-second order kinetics for adsorption of carbaryl onto NBD

\section{Optimization (Criteria-I)}

The first statistical optimization creates a point that maximizes the desirability function. To find maximum desirability, all the factors were within the range 2-10 of $\mathrm{pH}, 0.01-0.1 \mathrm{~g}$ of adsorbent dose, and 5-20 ppm initial concentration. The importance of each goal was altered in relation to the other goals. Figure 14a shows a ramp desirability that was generated from 30 optimum points through numerical optimization using the software. By choosing from 30 starting points in the response surface changes, the best local maximum was found to be at $\mathrm{pH} 5.51$, adsorbent dose of $0.1 \mathrm{~g}$, and initial concentration of $12.38 \mathrm{ppm}$; under this condition, carbaryl removal was $99.744 \%$ and desirability was 1.000 . These optimum values predicted by the Design-Expert software were checked experimentally in laboratory which showed carbaryl removal by NBD close to $99 \%$. Overall, the obtained value of desirability depicts that the estimated function may characterize the experimental model under required conditions [35].

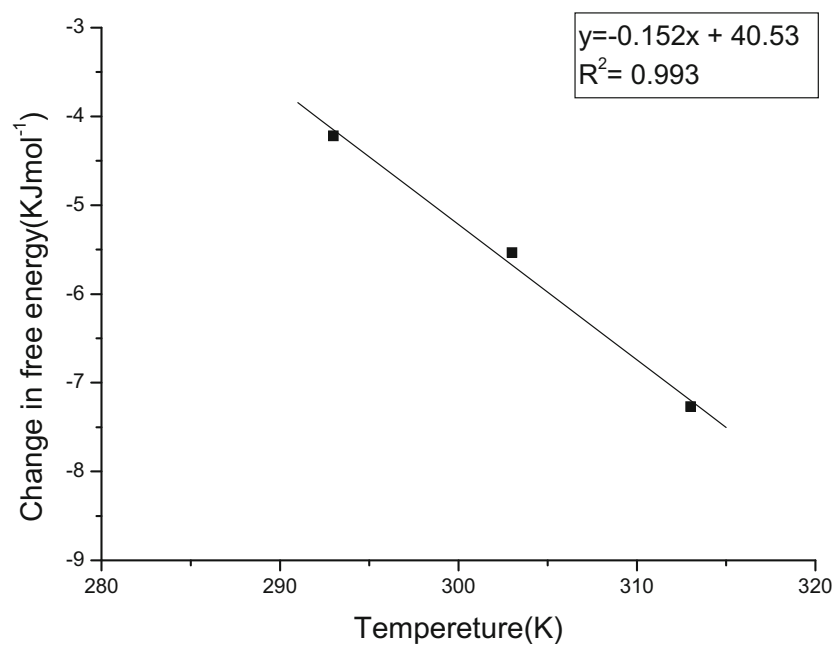

Fig. 13 Plot of change of free energy $\left(\Delta G^{\circ}\right)$ vs temperature $(T)$
Table 8 Summary of parameters for various thermodynamic parameters

\begin{tabular}{lllll}
\hline$\Delta \mathrm{G}^{0}\left(\mathrm{KJ} \mathrm{mol}^{-1}\right)$ & $\Delta \mathrm{H}^{0}\left(\mathrm{KJ} \mathrm{mol}^{-1}\right)$ & \multicolumn{2}{c}{$\Delta \mathrm{S}^{0}\left(\mathrm{KJ} \mathrm{mol}^{-1} \mathrm{~K}^{-1}\right)$} \\
\hline $293 \mathrm{~K}$ & $303 \mathrm{~K}$ & $313 \mathrm{~K}$ & 40.53 & 0.152 \\
-4.22 & -5.54 & -7.27 & & \\
\hline
\end{tabular}

\section{Optimization (Criteria-II)}

In order to find the maximum adsorption capacity under economically viable condition in the second optimization process, the goal was set as "in range" for $\mathrm{pH}$, "maximum" for adsorbent dose, and "minimum" for initial concentration, respectively. After optimization, the software detected 10 different solutions. Among these solutions, the best condition was found at $\mathrm{pH} 5.86$, adsorbent dose at 0.01 , and initial concentration at 18.29 . Under this condition, carbaryl removal is $82.6 \%$ and desirability is 0.822 (Fig. 14b). Now, when the software predicted the optimum values that were checked experimentally, this resulted in $78 \%$ of carbaryl removal by NBD. Using these values, the maximum adsorption capacity was also calculated (using Eq. 1) and found to be $146.3 \mathrm{mg} \mathrm{g}^{-1}$. Furthermore, based on maximum adsorption capacity and economical use of adsorbent, a second optimization procedure was preferred for the removal of carbaryl by NBD. A similar finding has been observed in percentage removal of $\mathrm{Cr}^{6+}$ by neem bark powder [32].

\section{Desorption Studies}

The possibility of recovery of adsorbent was investigated by conducting desorption studies. Regeneration of the adsorbent also makes the treatment process more economical. In the present study, desorption of carbaryl from carbaryl-loaded NBD was possible by employing 2(M) $\mathrm{NaOH}$ solution, which performed well with a desorption efficiency close to $94 \%$. Therefore, the adsorbent was recovered well and will not be a cause of pollution in the future.

\section{Comparison of Neem Bark Dust with Other Adsorbents}

For a direct and meaningful comparison, the maximum amount of carbaryl adsorbed on NBD has been compared to the maximum carbaryl adsorption capacity of NBD with other reported sorbents under different $\mathrm{pH}$ and are presented in Table 9. From the table, it is clear that the maximum sorption capacity of NBD for carbaryl is comparable and moderately higher than that of many corresponding sorbent materials. The easy availability and cost effectiveness of NBD are some additional advantages, which makes it a better adsorbent for treatment of carbaryl. 


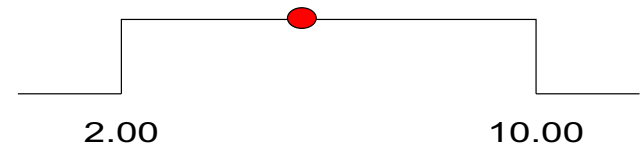

$\mathrm{pH}=5.51$

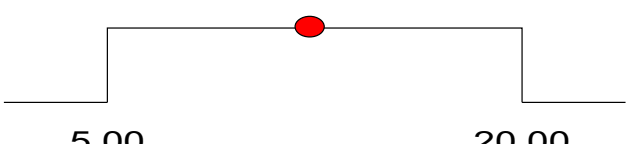

concn $=12.38$

Desirability $=1.000$

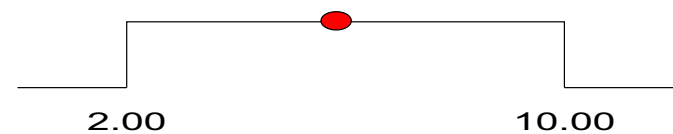

$\mathrm{pH}=5.86$

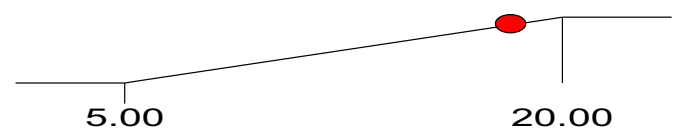

concn $=18.29$

\section{Desirability $=0.822$}

Fig. 14 RAMP plots for $\mathbf{a}$ first and $\mathbf{b}$ second optimization procedure

Table 9 Adsorption capacity of various adsorbents as reported in literature

\begin{tabular}{lll}
\hline Adsorbent & $\begin{array}{l}\text { Maximum adsorption } \\
\text { capacity }(\mathrm{mg} / \mathrm{g})\end{array}$ & References \\
\hline $\begin{array}{l}\text { Porogen-treated banana } \\
\text { pith carbon }\end{array}$ & 45.9 & {$[19]$} \\
$\begin{array}{l}\text { Clay } \\
\text { Pistia stratiotes biomass }\end{array}$ & 10.75 & {$[22]$} \\
Lemna major biomass & 6.1 & {$[11]$} \\
Neem Bark Dust & 146.3 & {$[23]$} \\
\hline
\end{tabular}

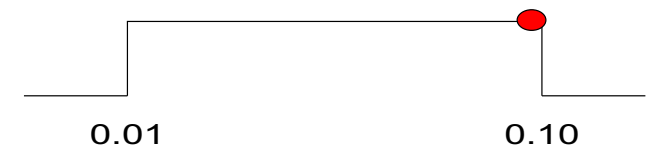

Dose $=0.10$

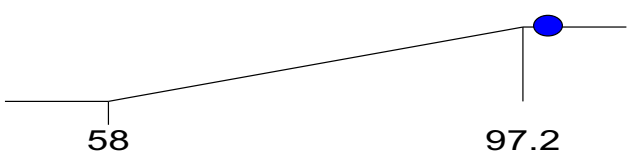

$\%$ Removal $=99.7439$

(a)

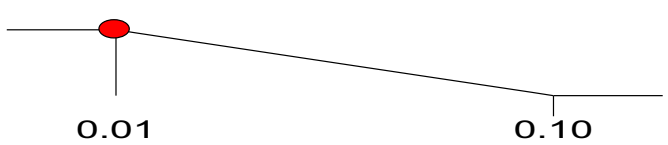

Dose $=0.01$

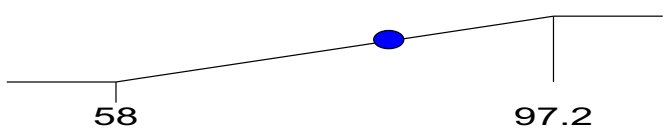

$\%$ Removal $=82.5999$

(b)

\section{Conclusions}

At first, optimum values of particle size, stirring rate, and equilibrium contact time were chosen. Thereafter, the statistical design (BBD) selected from RSM was applied to analyze carbaryl removal from aqueous solutions by NBD as a function of several parameters, viz., $\mathrm{pH}$ (A), adsorbent dose (B), and initial concentration (C). Results obtained from ANOVA explained that carbaryl removal is highly affected by adsorbent dose, $\mathrm{pH}$, and the combined effect of solution $\mathrm{pH}$ with the other factors (viz, adsorbent dose, initial concentration). According to this model, the best optimized conditions are 
$\mathrm{pH}$ (5.86), biomass dose $(0.01 \mathrm{~g})$, and initial concentration (18.29 ppm). Under these conditions, the experimental maximum adsorption capacity is $146.3 \mathrm{mg} / \mathrm{g}$ of carbaryl from aqueous solutions, when using NBD. Hence, RSM has given important information on interactions between the factors and helps to detect possible optimum values of the studied factors. The kinetic studies displayed the applicability of pseudosecond order kinetics. The adsorption equilibrium data was found to fit best with Langmuir adsorption isotherm. Thermodynamic parameters such as change in free energy, change in enthalpy, and change in entropy indicate the feasibility and the endothermic and spontaneous nature of adsorption. Finally, it can be concluded that the reported results presented in this study indicate that neem bark dust has great potential as an easily available natural adsorbent for removal of carbaryl in wastewater management and treatment.

Acknowledgments The authors are thankful to the Department of Environmental Science, University of Burdwan, West Bengal, India, for providing active support of this work.

\section{References}

1. Yadamari T, Yakkala K, Battala G, Gurijala RN (2011) Biosorption of malathion from aqueous solutions using herbal leaves powder. Am J Anal Chem 2:37-45

2. Salman JM, Njoku VO, Hameed BH (2011) Adsorption of pesticides from aqueous solution onto banana stalk activated carbon. Chem Eng J 174:41-48

3. Martino MD, Sannino F, Pirozzi D (2015) Removal of pesticide from wastewater: contact time optimization for a two-stage batch stirred adsorber. J Environ Chem Eng 3:365-372

4. Singh KP, Malik A, Mohan D, Sinha S (2005) Persistence organochlorine pesticide residues in alluvial groundwater aquifers of Gangetic plains, India. Bull Environ Contam Toxicol 74:162-169

5. Derylo-Marczewska A, Blachnio M, Marczewski AW, Swiatkowski A, Tarasiuk B (2010) Adsorption of selected herbicides from aqueous solutions on activated carbon. J Therm Anal Calorim 101:785-794

6. Guidelines for drinking water quality (1984) World Health Organization, vol.1. Geneva, Switzerland

7. Droste RL (1997) Theory and practice of water and wastewater treatment. Wiley and Sons, Canada

8. Katsumata H, Kobayashi T, Kaneco S, Suzuki T, Ohta K (2011) Degradation of linuron by ultrasound combined with photo-Fenton treatment. Chem Eng J 166:468-473

9. Ugurlu M, Karaoglu MH (2011) $\mathrm{TiO}_{2}$ supported on sepiolite: preparation, structural and thermal characterization and catalytic behaviour in photocatalytic treatment of phenol and lignin from olive mill wastewater. Chem Eng J 166:859-867

10. Gong J, Yang C, Pu W, Zhang J (2011) Liquid phase deposition of tungsten doped $\mathrm{TiO}_{2}$ films for visible light photoelectrocatalytic degradation of dodecylbenzenesulfonate. Chem Eng J 167:190197

11. Zhou T, Lim TT, Chin SS, Fane AG (2011) Treatment of organics in reverse osmosis concentrate from a municipal wastewater reclamation plant: feasibility test of advanced oxidation processes with/without pretreatment. Chem Eng J 166:932-939
12. Rajashekara MHM, Manonmani HK (2007) Aerobic degradation of technical hexachlorocyclohexane by a defined microbial consortium. J Hazard Mater 149:18-25

13. Banasiak LJ, Van der Bruggen B, Schafer AI (2011) Sorption of pesticide endosulfan by electrodialysis membranes. Chem Eng $\mathrm{J}$ 166:233-239

14. Maldonado MI, Malato S, Perez-Estrada LA, Gernjak W, Oller I, Domenech X, Peral J (2006) Partial degradation of five pesticides and an industrial pollutant by ozonation in a pilotplant scale reactor. J Hazard Mater 38:363-369

15. Al-Muhtaseb AH, Ibrahim KA, Albadarin AB, Ali-khashman $\mathrm{O}$, Walker GM, Ahmad MN (2011) Remediation of phenolcontaminated water by adsorption using poly (methyl methacrylate) (PMMA). Chem Eng J 168:691-699

16. Chattoraj S, Mondal NK, Das RP, Sadhukhan B (2014) Biosorption of carbaryl from aqueous solution onto Pistia stratiotes biomass. Appl Water Sci 4:79-88

17. Boudesocque S, Guillon E, Aplincourt M, Martel F, Noael S (2008) Use of a low cost biosorbent to remove pesticides from waste water. J Environ Qual 37:631-638

18. Sudhakar Y, Dikshit AK (1999) Adsorbent selection for endosulfan removal from waste water environment. J Environ Sci Health, Part B 34:97-118

19. Chatterjee S, Das SK, Chakravarthy R, Chakrabarti A, Ghosh S, Guha AK (2010) Interactive of malathion, an organophosphorus pesticide with Rhizopus oryzea bio-mass. J Hazard Mater 174: 47-53

20. Kumar P, Singh H, Kapur M, Mondal MK (2014) Comparative study of malathion removal from aqueous solution by agricultural and commercial adsorbents. J Water Process Eng 3:67-73

21. Roy P, Dey U, Chattoraj S, Mukhopadhyay D, Mondal NK (2015) Modeling of the adsorptive removal of arsenic (III) using plant biomass: a bioremedial approach. Appl Water Sci. doi:10.1007 /s13201-015-0339-2

22. Chattoraj S, Sadhukhan B, Mondal NK (2013) Predictability by Box-Behnken Model for carbaryl adsorption by soils of Indian Origin. J Environ Sci Health, Part B 48:626-636

23. Chattoraj S, Mondal NK, Das B, Roy P, Sadhukhan B (2014) Carbaryl removal from aqueous solution by Lemna major biomass using response surface methodology and artificial neural network. J Environ Chem Eng 1920-1928

24. Gupta SK, Saxena PN (2003) Carbaryl-induced behavioural and reproductive abnormalities in the earthworm Metaphire posthuma: a sensitive model. Altern Lab Anim 31:587-593

25. U.S. Environmental Protection Agency (2003) Office of Pesticide Programs, Environmental Fate and Effect Division. Revised EFED risk assessment of carbaryl in support of the registration eligibility decision, Washington. DC.

26. Sathishkumar M, Choi JG, Ku CS, Vijayaraghavan K, Binupriya AR, Yun SE (2009) Carbaryl sorption by porogen-treated banana pith carbon. Adsorption Sci Technol 26:679-686

27. Singh RP, Singh S, Srivastava G (2011) Adsorption thermodynamics of carbaryl onto four texturally different Indian soils. Adsorption Sci Technol 29:277-288

28. Mondal NK, Chattoraj S, Sadhukhan B, Das B (2013) Evaluation of carbaryl sorption in alluvial soil. Songklanakarin J Sci Technol 35: 727-738

29. Ouardi ME, Alahiane S, Qourzal S, Abaamrane A, Assabbane A, Douch J (2013) Removal of carbaryl pesticide from aqueous solution by adsorption on local clay in agadir. Am J Anal Chem 4:72-79

30. Naiya TK, Chowdhury P, Bhattacharya AK, Das SK (2009) Saw dust and neem bark as lowcost natural biosorbent for adsorptive removal of $\mathrm{Zn}$ (II) and $\mathrm{Cd}$ (II) ions from aqueous solutions. Chem Eng J 148:68-79

31. Mishra V, Balomajumder C, Agarwal VK (2011) Biosorption of $\mathrm{Zn}(\mathrm{II})$ ion onto surface of Cedrus deodara sawdust: studies on 
isotherm modelling and surface characterization. I J Chem Soc Appl 2:179-185

32. Saravana Kumar MP, Phanikumar BR (2013) Response surface modelling of $\mathrm{Cr}^{6+}$ adsorption from aqueous solution by neem bark powder: Box-Behnken experimental approach. Environ Sci Pollut Res 20:1327-1343

33. Bhattacharyya KG, Sharma A (2005) Kinetics and thermodynamics of methylene blue adsorption on neem (Azadirachta indica) leaf powder. Dyes Pigments 65:51-59

34. Srivastava R, Rupainwar DC (2010) Liquid phase adsorption of indigo carmine and methylene blue on neem bark. Desalin Water Treat 24:74-84

35. Sadhukhan B, Mondal NK, Chattoraj S (2014) Biosorptive removal of cationic dye from aqueous system: a response surface methodological approach. Clean Techn Environ Policy 16:1015-1025

36. Chowdhury S, Chakraborty S, Saha PD (2013) Response surface optimization of a dynamic dye adsorption process: a case study of crystal violet adsorption onto $\mathrm{NaOH}$-modified rice husk. Environ Sci Pollut Res 20:1698-1705

37. Myers RH, Montgomery DC (2002) Response surface methodology: process and product optimization using designed experiments, 2nd edn. Wiley, USA

38. Garg UK, Kaur MP, Sud D, Garg VK (2009) Removal of hexavalent chromium from aqueous solution by adsorption on treated sugarcane bagasse using response surface methodological approach. Desalination 249:475-479

39. Mourabet M, Rhilassi AE, Boujaady HE, Bennani-Ziatni M, Taitai A (2014) Use of response surface methodology for optimization of fluoride adsorption in an aqueous solution by Brushite. Arab J Chem. doi:10.1016/j.arabjc.2013.12.028

40. Mondal MK (2009) Removal of $\mathrm{Pb}$ (II) ions from aqueous solution using activated tea waste: adsorption on a fixed-bed column. J Environ Manag 90:3266-3271

41. Stansbury HA, Miskus R (1964) Analytical methods for pesticides, plant growth regulators and food additives, vol 2. Academic Press, New York, $\mathrm{p} 437$

42. Jana TK, Das B (1997) Sorption of carbaryl (1-napthyl N-methyl carbamate) by soil. Bull Environ Contam Toxicol 59:65-71

43. Stat-Ease Inc (2009) Design-Expert 7 for Windows: Software for Design of Experiments (DOE), Minneapolis, MN, http://www. statease.com

44. Coates J (2000) Interpretation of infrared spectra, A practical approach, Encyclopedia of Analytical Chemistry, R.A. Meyers (Ed.), John Willy and Sons Ltd, Chichester, pp 10815-10837

45. De Oliveira Brito SM, Andradeb HMC, Soares LF, De Azevedo RP (2010) Brazil nut shells as a new biosorbent to remove methylene blue and indigo carmine from aqueous solutions. J Hazard Mater 174:84-92

46. Chowdhury S, Saha P (2010) Sea shell powder as a new adsorbent to remove Basic Green 4 (Malachite Green) from aqueous solutions: Equilibrium, kinetic and thermodynamic studies. Chem Eng J 164:168-177

47. Bhaumik R, Mondal NK, Chattoraj S, Datta JK (2013) Application of response surface methodology for optimization of fluoride removal mechanism by newly developed biomaterial. Am J Anal Chem 4:404-419

48. Das B, Mondal NK, Roy P, Chattaraj S (2012) Equilibrium, kinetic and thermodynamic study on chromium (VI) removal from aqueous solution using Pistia stratiotes biomass. Chem Sci Trans 2:85104

49. Tripathi P, Srivastava VC, Kumar A (2009) Optimization of an azo dye batch adsorption parameters using Box-Behnken design. Desalination 249:1273-1279

50. Cheng Z, Zhang L, Guo X, Jiang X, Li T (2015) Adsorption behavior of direct red 80 and congo red onto activated carbon/surfactant: process optimization, kinetics and equilibrium. Spectrochim Acta A 137:1126-1143

51. Montgomery DC (1996) Design and analysis of experiments, fourth ed., Wiley, USA. doi:10.1007/s11356-012-0981-2

52. Korbahti BK, Rauf MA (2008) Application of response surface analysis to the photolytic degradation of Basic Red 2 dye. Chem Eng J 138:166-171

53. Agarry SE, Owabor CN, Yusuf RO (2012) Enhanced bioremediation of soil artificially contaminated with kerosene: optimization of biostimulation agents through statistical experimental design. J Pet Environ Biotechnol 3:120. doi:10.4172/2157-7463.1000120

54. Belsley DA, Kuh E, Welsh RE (1980) Regression diagnostics: identifying influential data and sources of collinearity. Wiley series in probability and mathematical statistics. John Wiley and Sons, New York

55. Chowdhury S, Saha PD (2011) Biosorption kinetics, thermodynamics and isosteric heat of sorption of $\mathrm{Cu}$ (II) onto Tamarindus indica seed powder. Colloids Surf B: Biointerfaces 88:697-705

56. Babu BV, Gupta S (2008) Adsorption of Cr (VI) using activated neem leaves kinetic studies. J Adsorpt 14:85-92

57. Gulen J, Altın Z, Ozgur M (2013) Adsorption of amitraz on the clay. Am J Eng Res 2:1-8

58. Kundu S, Gupta AK (2006) Arsenic adsorption onto iron oxidecoated cement (IOCC): regression analysis of equilibrium data with several and their optimization. Chem Eng J 122:93-106

59. Sanyal P, Saha SK (2010) Assessment of the removal of cadmium present in wastewater using soil-admixture membrane. Desalination 259:131-139

60. Ho YS, McKay G (1999) Pseudo-second order model for sorption processes. Process Biochem 34:451-465

61. Feng YJ, Zhang ZH, Gao P (2010) Adsorption behavior of EE2 (17 $\alpha$-ethinylestradiol) onto the inactivated sewage sluge. Kinetics, thermodynamics and influence factors. J Hazard Mater 175:970 976 